\title{
Parabrachial Nucleus Contributions to Glucagon-Like Peptide-I Receptor Agonist-Induced Hypophagia
}

\author{
Jennifer C Swick', Amber L Alhadeff', Harvey J Grill', Paula Urrea', Stephanie M Lee', Hyunsun Roh' and \\ John-Paul Baird*,i \\ 'Program in Neuroscience, Amherst College, Amherst, MA, USA; ²Department of Psychology, University of Pennsylvania, Philadelphia, PA, USA
}

\begin{abstract}
Exendin-4 (Ex4), a glucagon-like peptide-I receptor (GLP-IR) agonist approved to treat type 2 diabetes mellitus, is well known to induce hypophagia in human and animal models. We evaluated the contributions of the hindbrain parabrachial nucleus (PBN) to systemic Ex4induced hypophagia, as the PBN receives gustatory and visceral afferent relays and descending input from several brain nuclei associated with feeding. Rats with ibotenic-acid lesions targeted to the lateral PBN (PBNx) and sham controls received Ex4 (I $\mu \mathrm{g} / \mathrm{kg})$ before $24 \mathrm{~h}$ home cage chow or 90 min $0.3 \mathrm{M}$ sucrose access tests, and licking microstructure was analyzed to identify components of feeding behavior affected by Ex4. PBN lesion efficacy was confirmed using conditioned taste aversion (CTA) tests. As expected, sham control but not PBNx rats developed a CTA. In sham-lesioned rats, Ex4 reduced chow intake within $4 \mathrm{~h}$ of injection and sucrose intake within 90 min. PBNx rats did not show reduced chow or sucrose intake after Ex4 treatment, indicating that the PBN is necessary for Ex4 effects under the conditions tested. In sham-treated rats, Ex4 affected licking microstructure measures associated with hedonic taste evaluation, appetitive behavior, oromotor coordination, and inhibitory postingestive feedback. Licking microstructure responses in PBNx rats after Ex4 treatment were similar to sham-treated rats with the exception of inhibitory postingestive feedback measures. Together, the results suggest that the PBN critically contributes to the hypophagic effects of systemically delivered GLP-IR agonists by enhancing visceral feedback.

Neuropsychopharmacology (20I5) 40, 200 I-20I4; doi:I0.I038/npp.20I5.50; published online I8 March 2015
\end{abstract}

\section{INTRODUCTION}

Glucagon-like peptide-1 (GLP-1), an incretin synthesized and secreted by distal L cells of the small intestine upon intraluminal nutrient detection, is well known for its action on pancreatic $\beta$-cells to stimulate the release of insulin. GLP-1 mimetics have been introduced for the treatment of type 2 diabetes mellitus and they are a target for obesity treatment. Exendin-4 (Ex4), a long-acting GLP-1 analog resistant to in vivo degradation, originally found in the saliva of the Gila lizard (Heloderma suspectum), has been shown to improve $\mathrm{HbAlC}$ levels and induce weight loss in patients (Blevins, 2011; Bond, 2006; Buse et al, 2011). Consistent with the postulation that GLP-1-receptor ligands contribute to energy balance by reducing food intake, central and peripheral administration of Ex4 reduces food intake in a variety of species (see, eg, Edwards et al, 2001; Jessen et al, 2012; Scott and Moran, 2007; Szayna et al, 2000), and thus identification of the peripheral and central mechanisms mediating GLP-1 hypophagia is a flourishing and important topic of investigation.

\footnotetext{
*Correspondence: Professor J-P Baird, Program in Neuroscience, Amherst College, I 5 Mead Avenue, Room 326, Merrill Building, Amherst, MA 0 002, USA, Tel: +4I3 542 5828, Fax: + I 413542 2I45,

E-mail: jpbaird@amherst.edu

Received 20 October 2014; revised 10 January 2015; accepted 14 January 2015; accepted article preview online 23 February 2015
}

Ex4 is a potent agonist of the glucagon-like peptide-1 receptor (GLP-1R; (Göke et al, 1993) and GLP-1R mRNA is expressed peripherally in enteric and vagal nerves, the pancreas, stomach, intestines, and adipose tissue (Bullock et al, 1996; Nakagawa et al, 2004; Vahl et al, 2007), and centrally in cortical, hypothalamic, and hippocampal nuclei, as well as several hindbrain structures (Merchenthaler et al, 1999; Vrang and Larsen, 2010). Despite this wide distribution, central GLP-1 synthesis is limited to neurons of the nucleus of the solitary tract (NST) and dorsal reticular formation (Vrang and Larsen, 2010), although fibers containing GLP-1 generally complement the GLP-1R distribution and have been identified in several structures in the brain implicated in feeding control, including the arcuate nucleus of the hypothalamus, lateral hypothalamus, periventricular nucleus of the thalamus, dorsomedial hypothalamic nucleus, ventral tegmental area, nucleus accumbens, area postrema, dorsal motor nucleus, NST, and the parabrachial nucleus (PBN) of the pons (Grill, 2010; Hayes et al, 2008, 2009; McMahon and Wellman, 1998; Renner et al, 2012; Rinaman, 2010; Vrang and Larsen, 2010).

Research to identify brain structures mediating GLP-1 hypophagia to date has focused primarily on hypothalamic structures, though more recent work has attended to GLP-1R contributions in the ventral tegmental area and nucleus accumbens (Alhadeff and Grill, 2014; Dossat et al, 2011), and the hindbrain (Alhadeff et al, 2014; Hayes et al, 2008; 
Williams et al, 2009). In chronic supracollicular decerebrate rats, both fourth ventricle and peripheral Ex4 administration suppressed food intake, demonstrating that the caudal brainstem is sufficient to mediate Ex4 hypophagia (Hayes et al, 2008). Among brainstem structures, most work has focused on the NST. For example, RNAi knockdown of GLP-1 mRNA expression in the NST results in hyperphagia and weight gain (Barrera et al, 2011). However, to further understand the circuitry supporting GLP-1 hypophagia, proximal targets of the NTS within the brainstem are of primary interest. In this regard the $\mathrm{PBN}$ is a propitious candidate. The PBN processes first-order gustatory and visceral sensory signals relayed from the NST and it relays them to numerous midbrain and forebrain structures implicated in food intake control, including the nucleus accumbens, several hypothalamic nuclei, and the amygdalar complex (Karimnamazi et al, 2002; Karimnamazi and Travers, 1998; Lundy and Norgren, 2004; Norgren et al, 2006). Recent studies have documented direct monosynaptic connections between GLP-1-producing neurons in the NST and the PBN (Alhadeff et al, 2014), and both GLP-1R mRNA and GLP-1-immunopositive fibers have been identified within the PBN (Merchenthaler et al, 1999; Rinaman, 2010). Studies have also shown that peripheral doses of Ex4 stimulate Fos mRNA in PBN neurons, predominantly in the external lateral subnucleus of the PBN (Baraboi et al, 2011) that is commonly associated with processing of visceral afferent stimuli (Baird et al, 2001a, b; Fulwiler and Saper, 1984; Karimnamazi et al, 2002; Paues et al, 2006). It is worth noting that subdiaphragmatic vagotomy did not attenuate systemic Ex4-induced PBN Fos expression in the latter study, suggesting that the PBN might be activated directly by Ex4 (Kanoski et al, 2011), as Ex4 is also known to rapidly cross the blood-brain barrier (Kastin and Akerstrom, 2003). Therefore, Ex4 treatment likely activates PBN neurons through both direct and indirect (eg, vagus-NST-PBN) pathways.

Recently, we reported that direct PBN microinjections of Ex4 and the GLP-1R antagonist exendin-(9-39) (Ex9) respectively suppressed and increased food intake, indicating that GLP-1R signaling within the PBN physiologically contributes to food intake control (Alhadeff et al, 2014). Nevertheless, it remains unclear whether endogenous GLP-1 or long-acting systemic incretin treatments can sufficiently activate or require the $\mathrm{PBN}$ to affect food intake. In the current study we evaluated hypophagic responses to systemic Ex4 treatment in rats with bilateral neurochemical lesions of the PBN (PBNx), to better understand the role of the $\mathrm{PBN}$ in mediating responses to this FDA-approved incretin mimetic. Rats with PBN lesions generally lack the ability to either sense or integrate inhibitory visceral feedback with other food intake-relevant signals that is key to food learning and satiation processes (Calingasan and Ritter, 1993; Reilly, 1999; Trifunovic and Reilly, 2001). For example, PBNx rats cannot form a conditioned taste aversion (CTA), the avoidance of a novel tastant previously paired with an aversive gastrointestinal stimulus such as lithium chloride (LiCl; Flynn et al, 1991). In addition, $\mathrm{PBNx}$ rats exhibit impaired satiation responses to caloric gastrointestinal stimuli and to peripheral injections of the satiating hormones amylin and cholecystokinin (Becskei et al, 2007; Trifunovic and Reilly, 2001). Therefore, we confirmed PBN lesions in rats using CTA tests as measured through licking microstructure analysis (Baird et al, 2005;
Pelchat et al, 1983). Next, we monitored systemic Ex4 treatment effects on chow intake in $\mathrm{PBNx}$ and sham-operated control rats over a 24 -h period. In another experiment, the same PBNx and sham-operated control rats were trained to lick for a sucrose solution in a lickometer and the effects of Ex4 on licking microstructure were assessed because, to our knowledge, no prior studies have evaluated licking microstructure responses in intact rodents after systemic Ex4 treatment. Several measures of licking microstructure differentially correlate with the intensity of food stimuli along different portions of the alimentary canal; in particular, some measures can be used to distinguish visceral inhibitory feedback and gustatory evaluation responses, as well as oromotor coordination and visceral malaise (Baird et al, 2005; Davis, 1996; Davis and Smith, 1992; Spector et al, 1998). Therefore, licking microstructure analysis provides a rich analysis with which to characterize Ex4 hypophagia and it can help to identify which sensory-motor behavioral components of the Ex4 hypophagia response, if any, are impaired by a $\mathrm{PBN}$ lesion.

\section{MATERIALS AND METHODS}

\section{Subjects}

Adult male albino Sprague-Dawley rats (Charles River Laboratories, Wilmington, MA) individually housed in transparent cages $(48 \mathrm{~cm} \times 25 \mathrm{~cm} \times 15 \mathrm{~cm})$ in a temperaturecontrolled colony room under a 12-h light/dark cycle had ad libitum access to pelleted rat chow (LabDiet 5001, Brentwood, MO) and tap water, except where noted below. All procedures were approved by the Institutional Animal Care and Use Committee of Amherst College.

\section{Surgery}

Rats weighing 300-400 g were randomly assigned to one of the two groups. Rats in the $\mathrm{PBNx}$ group received bilateral ibotenic-acid infusions aimed at the PBN, whereas rats in the PBNsham group received comparable bilateral vehicle infusions to the PBN. Rats were anesthetized with a mixture of ketamine- $\mathrm{HCl}(108 \mathrm{mg} / \mathrm{kg}$, i.m. $)$ and xylazine $(9 \mathrm{mg} / \mathrm{kg}, \mathrm{i} . \mathrm{m}$. and administered subsequent boosters throughout surgery as needed to maintain the anesthetic plane. Anesthetized rats were placed in a stereotaxic instrument (Kopf Instruments, Tujunga, CA), and the skull was exposed and leveled. A $1.18 \mathrm{~mm}$ hole was drilled manually at $0.7 \mathrm{~mm}$ anterior to lambda and $2.0 \mathrm{~mm}$ lateral from the midline over each hemisphere. To avoid the traverse sinus, a $20^{\circ}$ rostral tilt was then used to lower a $26 \mathrm{~g}$ cannula guide (Plastics1, Roanoke, VA) $7.7 \mathrm{~mm}$ below the skull surface (Baird et al, 2001a,b). A $33 \mathrm{~g}$ injector fitted to protrude $1 \mathrm{~mm}$ from the guide was inserted into the cannula and either $0.4 \mu \mathrm{l}$ ibotenic acid $(20 \mu \mathrm{g} / \mu \mathrm{l})$ or vehicle (phosphate-buffered saline (PBS) $0.15 \mathrm{M}$, $\mathrm{pH}$ 7.4) was infused at a rate of $0.04 \mu \mathrm{l} / \mathrm{min}$ using PE tubing via a $1.0 \mu$ l Hamilton syringe loaded into a programmable syringe pump (KD Scientific KD100, Holliston, MA). To maximize infusate diffusion and minimize backflow up the guide, the injector was left in place for 10 min after infusion. Thereafter, the cannula and injector assembly was carefully removed and the process repeated in the other hemisphere. Subsequently, the incision was closed with wound clips 
and the rat was routinely monitored for recovery according to IACUC-established protocols.

\section{Experimental Procedures}

Before the Ex4 experiments, PBN lesions were behaviorally confirmed. After recovery from surgery (3-7 days), PBNsham and PBNx rats underwent a 3-day CTA experiment. Rats were water-deprived in the home cage $23.5 \mathrm{~h}$ before each test day. On day 1, rats received an intraperitoneal (i.p.) injection of $0.15 \mathrm{M}$ lithium chloride ( $2 \%$ body weight) immediately after 30 -min access to a spout containing a novel tastant, $0.12 \mathrm{M}$ sodium chloride $(\mathrm{NaCl})$, in a lickometer (AC-108, DiLog Instruments, Tallahassee, FL). On days 2 and 3, rats were given $30 \mathrm{~min}$ access to $0.12 \mathrm{M} \mathrm{NaCl}$. At $30 \mathrm{~min}$ after access to $0.12 \mathrm{M} \mathrm{NaCl}$ on all 3 test days, rats were given 15 min water access in the home cage to ensure adequate fluid repletion. After CTA testing, rats were monitored and confirmed to have normalized water intake and body weight before further experimentation (3-5 days).

Experiment 1: effects of $P B N$ lesion on Ex4-induced hypophagia: $24 \mathrm{~h}$ chow intake. Experiments 1 and 2 were conducted using a within-subjects design such that rats in each test group ( $\mathrm{PBNx}$ and $\mathrm{PBNsham}$ ) completed each experiment in counterbalanced order. For experiment 1, chow pellets were removed and rats were offered powdered chow ad libitum in the home cage in small dishes adhered to the cage floor. The $24 \mathrm{~h}$ chow intake was measured manually to $0.01 \mathrm{~g}$ and dishes were refilled daily at the onset of the dark cycle. Once the chow intake stabilized (3-5 days), rats were randomly assigned to one of the two injection conditions. On injection days, rats were food deprived $4 \mathrm{~h}$ before the onset of the dark cycle. At 10 min before onset of the dark cycle, they received an i.p. injection of either $1 \mu \mathrm{g} / \mathrm{ml} / \mathrm{kg}$ Ex4 (California Peptide, Napa, CA) or vehicle (PBS, $1 \mathrm{ml} / \mathrm{kg}$ ). Powdered chow was returned to the cage at the onset of the dark cycle and measurements were taken at 1, 2, 4, 8, and $24 \mathrm{~h}$. After 2 rest days during which the rats continued to be offered chow ad libitum, the injection test was repeated, exposing rats to the opposite dose condition. Concluding testing, powdered chow was removed and the rats were returned to ad libitum access to chow pellets in the home cage.

Experiment 2: effects of PBN lesion on Ex4-induced hypophagia: sucrose licking microstructure. Rats were transported daily from home cages to individual lickometer test cages $(48 \mathrm{~cm} \times 25 \mathrm{~cm} \times 15 \mathrm{~cm})$ and initially trained to lick $0.5 \mathrm{M}$ sucrose from a spout situated in a slit in the wall for $30 \mathrm{~min}$ until adequate intake (at least $5 \mathrm{ml}$ ) was reached (3-5 days). Rats were then offered the test solution, $0.3 \mathrm{M}$ sucrose, for 90 min over 2-3 days to allow compensation for negative contrast before experiment onset. The experiment then consisted of two drug condition tests, as in experiment 1. On test days, rats received counterbalanced i.p. injections of either $1 \mu \mathrm{g} / \mathrm{ml} / \mathrm{kg}$ Ex4 or vehicle (PBS) $10 \mathrm{~min}$ before being placed in the lickometer for $90 \mathrm{~min}$, with access to $0.3 \mathrm{M}$ sucrose. For the 2 days between drug injections the rats were offered $0.3 \mathrm{M}$ sucrose in the lickometer for $90 \mathrm{~min}$ with no treatment.

\section{Histology}

At the conclusion of all testing, $\mathrm{PBNx}$ and $\mathrm{PBNsham}$ rats received a surgical dose of ketamine- $\mathrm{HCl} / \mathrm{xylazine}$ followed by a lethal dose of Sodium Pentobarbital (100 mg/kg, i.p.) and they were then transcardially perfused with $0.9 \%$ saline followed by $10 \%$ formalin. Fixed brains were harvested and stored in a $20 \%$ sucrose $/ 10 \%$ formalin solution for at least $48 \mathrm{~h}$ to allow sectioning. Coronal sections $(50 \mu \mathrm{m})$ of the $\mathrm{PBN}$ region were taken using a cryostat (Thermo Scientific HM550, Thermo Fisher Scientific, Waltham, MA) and somata were stained with $0.5 \%$ cresyl violet stain (Sigma Aldrich, St Louis, MO). Sections containing the $\mathrm{PBN}$ region were analyzed at $\times 40$ magnification with an Olympus BX51 microscope equipped with a DP72 digital camera $(12 \mathrm{mpx}$; Olympus America Diagnostics, Leeds, MA) and a dark-field condenser.

\section{Data Analysis}

PBNx and PBNsham brains were analyzed for gliosis, the presence or absence of PBN subnuclei, and visible borders of the PBN. Animals with lesions that did not have damage to at least half of each PBN were considered to have inadequate lesions. Measurements of the lateral PBN (LPBN) depth from the brachium conjuctivum $(b c)$ to the ventral spinocerebellar tract $(v s c)$ or to the fourth ventricle border (depending on rostrocaudal location) were made using microscope software (DP2-BSW, Olympus). Two measurements-from the dorsal edge of the stereotaxically lateral or 'tail' end of the $b c$ to the dorsolateral border of the PBN, and from dorsal edge of the stereotaxically medial 'neck' of the $b c$ to the dorsolateral border of the $\mathrm{PBN}$-were taken at three rostrocaudal levels of the PBN. The first was in the caudal region of the PBN where the mescencephalic trigeminal nucleus (Mes5) merges with the locus ceruleus; the second is the middle region where the Mes5 merges ventrally with the stereotaxically medial 'head' of the $b c$; and the third is the rostral PBN region were Mes5 is observed to extend through and dorsally emerge from the stereotaxically medial 'head' of the $b c$. All measurements were taken perpendicular to the oblique plane of long axis of the $b c$ using a line of best fit drawn through the middle of the $b c$. All measurements were then averaged to obtain a representative value of the lateral PBN depth for each PBN. The hemispheric PBN sizes were then averaged for each brain and the correlation of LPBN depth with the extent of CTA behavior (reduction of $\mathrm{NaCl}$ intake on day 2 relative to day 1) and the Ex4 sucrose intake effect (vehicle intake minus Ex4 intake) was determined.

The temporal distribution of licking was analyzed using a variety of custom-made programs (Baird et al, 1999, 2005) to characterize several previously established licking pattern measures, as follows. Meal analyses were limited to the first meal in the $90 \mathrm{~min}$ test session and meal size $(\mathrm{ml})$ was calculated as the number of licks in the meal (first lick of the first burst to last lick of the last burst) (Baird et al, 2005; Spector et al, 1998). The end of the meal was defined by a pause in licking for $\geq 10 \mathrm{~min}$ (Baird et al, 2006). Meal duration ( $\mathrm{min}$ ) was defined as the session time of the last lick in the meal minus the session time of the first lick in the meal. To analyze ingestion rate over the course of the meal we divided meals temporally into thirds, calculating the 
mean lick rate (licks/min) for each meal third (Baird et al, 2006; Spector et al, 1998). A licking burst was defined as three or more consecutive licks with no interlick interval (ILI) exceeding $1 \mathrm{~s}$. Thus, pauses of $>1 \mathrm{~s}$ determined burst termination (Spector et al, 1998). The burst count therefore represents the number of lick bursts in the meal. The mean burst size (licks/burst) was calculated as the cumulative number of licks in all bursts in the meal divided by the burst count. Mean pause duration (s) was calculated as the cumulative time of all bursts in the meal subtracted from meal duration and divided by the number of pauses in the meal (equal to the burst count minus one). To minimize artifact lick registrations because of nonlingual spout contacts, meal onset was defined as the first lick of the first burst containing at least three licks (Baird et al, 2006). The initial lick rate was the number of licks in the first min of the meal. The initial burst size was the number of licks in the first burst of the meal. Because $>95 \%$ of all ILIs in a meal are $<250 \mathrm{~ms}$ (in rats) and are normally distributed below this cutoff (Baird et al, 2005, 2006; Davis, 1996; Spector et al, 1998), the average duration of ILIs $<250 \mathrm{~ms}$ was determined to measure oromotor coordination. Oromotor coordination was also assessed by determining the mean lick volume (volume per lick), by dividing the measured session intake volume by the number of licks in the test session. The proportion of moderately long ILIs $(250-1999 \mathrm{~ms})$ relative to all ILIs in the meal was also calculated because increases in this ratio have been associated with aversive taste responses (Baird et al, 2005).

All statistics were performed using Systat 10.0 software (Systat Software, San Jose, CA). Taste aversion data were analyzed using a $2 \times 3$ mixed factors ANOVA comparing lesion group (between subjects) and test day (repeated measures). Significant main effects or interactions were explored using paired Student's $t$-tests. Lateral PBN depth and taste aversion strength/Ex4 intake effect data were compared using Pearson product-moment correlation analysis. Chow intake data were analyzed using a $2 \times 5$ repeated-measures ANOVA comparing drug condition (Ex4 and vehicle) and sample time (1, 2, 4, 8, and $24 \mathrm{~h}$ after injection) effects on cumulative chow intake for each group. A $2 \times 2$ mixed factors ANOVA was used to explore significant interaction terms, to compare lesion group (between subjects) and drug (Ex4/vehicle) at specific time epochs. Measures of licking microstructure for sucrose were analyzed using a single planned paired Student's $t$-test for each lesion group (Ex4 vs vehicle). The $\alpha$-value for statistical significance was set at 0.05 for all analyses. Values of $p<0.06$ and $p<0.07$ were considered to be 'marginally' significant.

\section{RESULTS}

\section{Lesion Analysis and CTA Tests}

Analysis of ibotenic-acid-injected brains indicated that 12 rats received bilateral lesions with significant damage $(>50 \%)$ throughout a majority of the PBN and these rats were analyzed as the PBNx group (eg, see Figure $1 \mathrm{~b}$ ). Other rats had a wide range of lesion outcomes including no lesion at all (intact; $n=5)$, 'mostly' intact $(<25 \%$ PBN damage; $n=5)$, weak unilateral lesions $(25-50 \%$ unilateral damage; $n=2)$, strong unilateral lesions $(>50 \%$ unilateral damage; $n=5)$, and mild bilateral lesions (25-50\% damage; $n=7$ ). Given the small size and erratic distribution of the lesions in these latter groups, their data were not analyzed further. Of the 26 rats that received sham lesions, 1 rat died before testing was completed, 3 were judged to have mild unilateral lesions, and 2 had misplaced injections; therefore, their data were not analyzed. Correct placement of the injections in both groups could also be determined by visible narrow dorsal-ventral 'track' damage due to the injection needle. Figure $1 \mathrm{~b}$ shows an example of a PBN with a lesion to most of the lateral PBN. Figure 1a shows a comparable level of the PBN in a PBNsham rat with no significant damage to the LPBN.

Lesions were behaviorally assessed by examining the intake-suppressive effects of a novel taste- $\mathrm{LiCl}$ pairing in the CTA test paradigm in each group using $0.12 \mathrm{M} \mathrm{NaCl}$ as the novel tastant. The PBNsham group markedly reduced their intake of the LiCl-paired taste as indicated by a significant decrease in $\mathrm{NaCl}$ intake on the second test day (lesion group $\times$ day interaction: $\mathrm{F}_{(2,60)}=4.80, p=0.012 ; t_{(19)}=9.68$, $p<0.001)$ that quickly extinguished by the third test day (Figure 1c). The PBNx group did not show a significant intake decline after $\mathrm{LiCl}$ injection, confirming that the lesion was effective $\left(t_{(11)}=1.83\right.$, NS; Figure 1c). The relationship of these behavioral results to PBN damage is further confirmed by a statistically significant positive correlation $(r=0.55$, $p<0.001$ ) between measured depth of the lateral PBN and the percentage of $\mathrm{NaCl}$ intake decline after $\mathrm{LiCl}$ injection on day 2 relative to lick counts for $\mathrm{NaCl}$ on day 1 (Figure 1d).

Analysis of licking microstructure measures showed that the reduction of licking for $\mathrm{NaCl}$ in the $\mathrm{PBNsham}$ group after $\mathrm{LiCl}$ injections was characterized by a marked reduction in the number of licks (Figure 1c), the mean size of bursts of licks, the initial rate of ingestion, the average ingestion rate, and the mean lick volume (Table 1). The reduction was not related to lick frequency/oromotor coordination deficiency because the mean of ILIs $<250 \mathrm{~ms}$ was not affected (Table 1 ). Overall, rats were more hesitant at the spout as indicated by expression of many more but smaller bursts of licking, a fivefold increase in the number of ILIs ranging from $250 \mathrm{~ms}$ to $2 \mathrm{~s}$ in duration, and a significant increase in the overall proportion of pause time during the meal. This pattern of results is nearly identical to our prior analysis of CTA responses in intact rats (Baird et al, 2005).

In contrast to the PBNsham group, $\mathrm{PBNx}$ rats showed almost none of the effects of $\mathrm{LiCl}$ observed in the sham group. A smaller but statistically significant reduction in the mean lick volume after $\mathrm{LiCl}$ injection was the only significant effect observed in this group (Table 1).

\section{Effects of PBN Lesion on Ex4-Induced Hypophagia: $24 \mathrm{~h}$ Chow Intake}

There was no significant difference in chow intake between lesion groups during vehicle conditions as there was no significant lesion group main effect $(\mathrm{F}<1, \mathrm{NS})$ or lesion group $\times$ epoch interaction $\left(\mathrm{F}_{(4,120)}=1.99, \mathrm{NS}\right)$. In the PBNsham group, Ex4 significantly reduced overall chow intake as indicated by a significant main effect (drug: $\mathrm{F}_{(1,19)}=8.97$, $p<0.007)$; the drug $\times$ time sample interaction was not statistically significant $(\mathrm{F}<1$; Figure $2 \mathrm{a})$. The $\mathrm{PBNx}$ group showed no main overall drug effect $\left(\mathrm{F}_{(1,11)}=2.02\right.$, NS), 
a

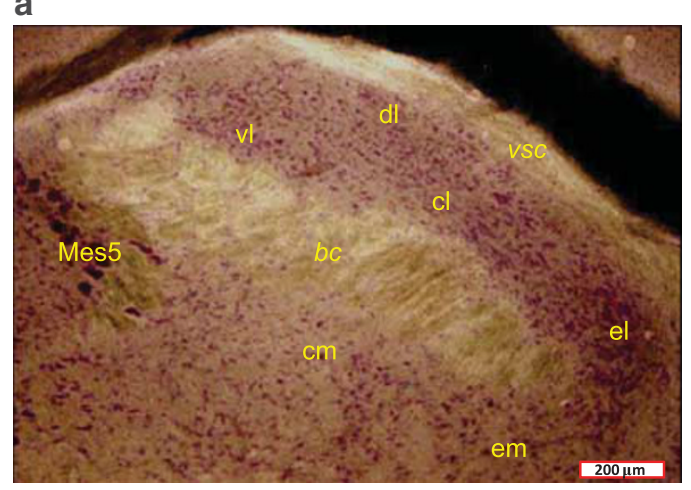

b

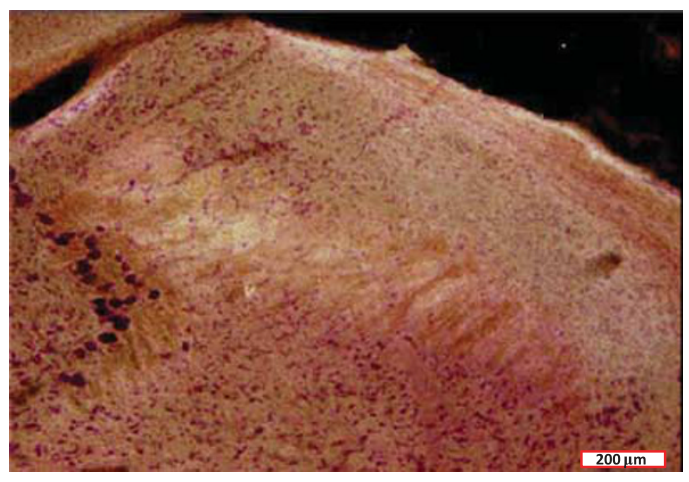

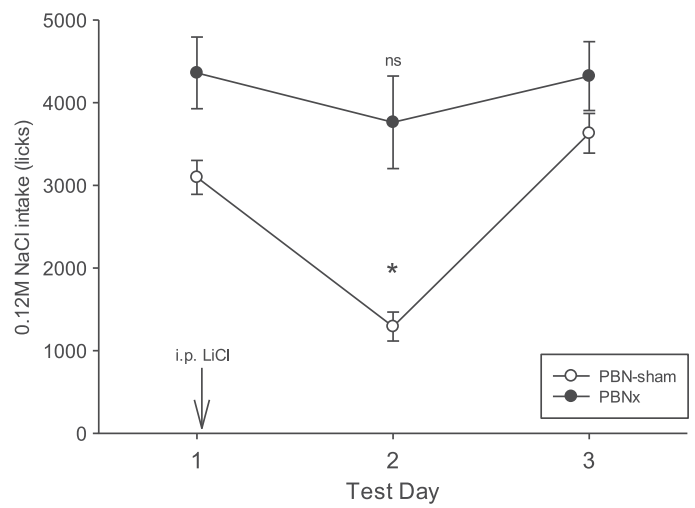

d



Figure I Left: Representative dark-field microphotographs ( $\times 40$ magnification) of the lateral parabrachial nucleus (LPBN) in an intact sham-lesioned rat (a) and an ibotenic acid-lesioned rat (b). In (a), clusters of neutral red-stained somata in all regions dorsal to the brachium conjuctivum are evident, and these include the ventral lateral, dorsal lateral, central lateral, and external lateral subnuclei. In the ibotenic-acid-lesioned rat there is a clear paucity of stained somata in all of these subnuclei, although somata loss is weaker in the rostral ventral lateral subnucleus. Note also the distinct lateral border of the lesion where intact somata from the external medial subnucleus are visible. In several PBN-lesioned brains the depth of the region dorsal to the brachium was also significantly attenuated. (c) $\mathrm{NaCl}$ intake responses in PBN-sham and PBN-lesioned rats. Water-deprived rats in both groups initially avidly consumed a normally preferred $\mathrm{NaCl}$ solution as measured by mean lick count $( \pm$ SEM) during a 30-min test. Both groups were injected with LiCl but only PBNsham-lesioned rats (open circles) exhibited intake reduction on the second test day. The CTA rapidly extinguished by the third day of testing. $* P<0.05$. (d) The extent of intake suppression induced by LiCl was positively and significantly correlated with the size of the LPBN. Intact sham-lesioned rats (open circles) with larger LPBN regions tended to exhibit fewer licks for $\mathrm{NaCl}$ after $\mathrm{LiCl}$ treatment. bc, brachium conjuctivum; cl, central lateral subnucleus; dl, dorsal lateral subnucleus; el, external lateral subnucleus; em, external medial subnucleus; Mes5, mesencephalic trigeminal motor nucleus; vl, ventral lateral subnucleus; vsc, ventral spinocerebellar tract.

although the drug $\times$ time interaction was significant in this group (interaction: $\mathrm{F}_{(4,44)}=3.18$ ), $p<0.03$; Figure $2 \mathrm{~b}$ ). To explore this interaction, the $\mathrm{PBNsham}$ and $\mathrm{PBNx}$ groups were directly compared at each sampling time. Two-way ANOVAs indicated statistically significant drug condition $x$ lesion group interactions for the $1 \mathrm{~h}\left(\mathrm{~F}_{(1,30)}=5.84, p<0.03\right)$ and $2 \mathrm{~h}$ time measurement periods $\left(\mathrm{F}_{(1,30)}=4.31, p<0.05\right)$, and a significant main effect of drug at the $4 \mathrm{~h}$ sampling time $\left(\mathrm{F}_{(1,30)}=9.15, p<0.005\right)$.

\section{Effects of PBN Lesion on Ex4-Induced Hypophagia: 90 min Sucrose Intake}

Analysis of sucrose intake for the 90 min session after Ex4 or vehicle injection revealed a significant difference in responses to Ex4 as a function of lesion condition, although there was no difference in baseline intake between the lesion groups under vehicle conditions $\left(t_{(30)}=-0.77\right.$, NS). Ex4 significantly reduced sucrose intake in the PBNsham group $\left(t_{(19)}=3.73, p<0.001\right)$ but not in the PBNx group $\left(t_{(11)}=0.20\right.$, NS; Figure 3a). Analysis of meal size revealed similar results; meal size was significantly smaller for the PBNsham group after Ex4 $\left(t_{(19)}=3.24, p<0.004\right)$, but not so for the PBNx group $\left(t_{(11)}=0.62\right.$, NS; Figure $\left.3 b\right)$. Moreover, the extent of intake reduction induced by Ex4 positively and significantly correlated with the measured width of the PBN, suggesting that rats with larger PBN lesions were less responsive to $\mathrm{Ex} 4$ (Figure 3c).

\section{Ex4 Effects on Sucrose Licking Microstructure in PBNx and PBNsham Rats}

Although PBN lesions counteracted Ex4-induced hypophagia, most of the microstructure responses induced by Ex4 in the PBNsham group were also observed in the PBNx group.

As sucrose intake was reduced by Ex4 in the PBNsham group, we expected that the duration of the meal would be reduced, but the meal duration after Ex4 was unexpectedly 
doubled in this intact group $\left(t_{(19)}=-3.11, p<0.006\right.$; Figure 4a). Equally surprising, Ex4 also doubled meal duration in the PBNx group $\left(t_{(11)}=-2.74, p<0.02\right)$. These results could indicate that $\mathrm{Ex} 4$ prolonged the periods in which rats were away from the spout, but there was no increase in the mean duration of pauses between bursts (PBNsham: $t_{(19)}=-0.87$, NS; PBNx: $t_{(11)}=-0.09$, NS; Figure $4 \mathrm{~b}$ ).

The prolonging of meal duration by $\mathrm{Ex} 4$ was due, rather, to an increase in the number of bursts (and pauses) in both the PBNsham $\left(t_{(19)}=-3.20, p<0.005\right)$ and $\mathrm{PBNx}$ groups $\left(t_{(11)}=-3.80, p<0.003\right.$; Figure $\left.5 \mathrm{a}\right)$, indicating that in both groups Ex4 induced rats to make additional returns to the spout over a longer period of time during the test session. Therefore, the reduction of sucrose intake by Ex4 would require a reduction of the mean burst size, and this was the case in both the PBNsham $\left(t_{(19)}=3.27, p<0.004\right)$ and the PBNx groups $\left(t_{(11)}=4.31, p<0.001\right.$; Figure $\left.5 \mathrm{~b}\right)$.

As noted, none of the aforementioned responses account for the ability of the PBN lesion to counteract Ex4 effects on sucrose intake. Rather, the intake effect was likely blocked due to lesion effects on ingestion rate measures, because the lesion groups showed the greatest Ex4 response differences in their rates of ingestion. Analysis of the rate of ingestion during the period of consumption was performed by analyzing meal thirds for each individual (Baird et al, 2005, 2006; Spector et al, 1998). Ex4 produced a more precipitous decline in the rate of ingestion in PBNsham rats beginning at an early phase in the meal, as there was a strong main effect of Ex4 with no significant interaction term, indicating that the rate of licking was slower than that for vehicle at all phases of the meal $\left(F_{(1,19)}=11.92, p<0.003\right.$; Figure 6a). For $\mathrm{PBNx}$ rats, Ex4 produced a less marked decline in the mean rate of licking across meal thirds that reached a marginal level of statistical significance for the main drug term $\left(\mathrm{F}_{(1,11)}=4.56, \quad p<0.06\right.$; Figure $\left.6 \mathrm{~b}\right)$. Paired comparisons further revealed that the rate of ingestion for $\mathrm{PBNx}$ rats was slower than vehicle condition in the first meal third $\left(t_{(11)}=2.93, p<0.01\right)$ but not the second or third phases of the meal ( $t \mathrm{~s}<1.3$, NS; Figure $6 \mathrm{~b})$. The effect of PBN lesion to block the Ex4 intake reduction therefore appeared to be mediated through the diminished capacity of Ex4 to suppress ingestion rate in $\mathrm{PBNx}$ rats in later phases of the meal. This conclusion is supported by a significant interaction when PBNsham and PBNx groups were directly compared under Ex4 conditions. Here there was no overall difference in ingestion rate between the two groups (lesion group main effect: $F<1, N S)$, but there was a significant meal third $x$ lesion group interaction $\left(\mathrm{F}_{(2,60)}=7.65, p<0.001\right.$; data not shown). No lesion group or interaction effects were observed when the two groups were compared under vehicle conditions (Fs $<2.21$, NS; data not shown). In addition, Ex4 had no effect on the initial lick rate or the initial burst size in either group ( $t s<1.7, \mathrm{NS}$; data not shown).

It is worth noting that Ex4 also markedly affected oromotor processing in both groups. Ex4 significantly reduced the mean lick volume in both groups (PBNsham: $t_{(19)}=3.51$, $p<0.002$; PBNx: $t_{(11)}=4.67, p<0.001$; data not shown) and Ex4 significantly prolonged the mean of ILIs $<250 \mathrm{~ms}$ (PBNsham: $t_{(19)}=-6.95, \quad p<0.001 ; \quad$ PBNx: $t_{(11)}=-7.87$, $p<0.001)$. Figure 7 shows the frequency distribution for ILIs in $5 \mathrm{~ms}$ bins for these groups and drug conditions. Together, these two results suggest that Ex4 prolonged 
a

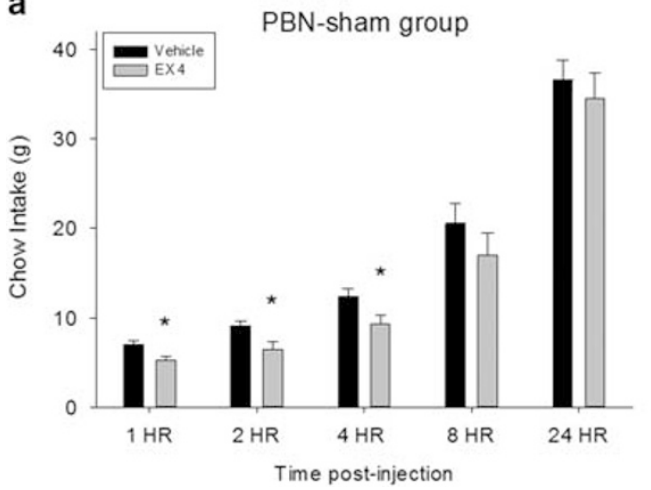

b



Figure 2 Exendin-4 ( $\mid \mu g / k g$, i.p.) significantly reduced chow intake in intact (PBNsham) but not PBN-lesioned (PBNx) rats. (a) Cumulative chow intake $\left(\right.$ mean + SEM) measured at I, 2, 4, 8, and $24 \mathrm{~h}$ time intervals in sham-lesioned rats $(n=20),{ }^{*} p<0.05$. (b) Cumulative chow intake (mean+SEM) measured at $\mathrm{I}, 2,4,8$, and $24 \mathrm{~h}$ time intervals in rats with bilateral PBN lesions $(n=12)$


Figure 3 (a) Mean 90 min $0.3 \mathrm{M}$ sucrose intake (+SEM) after vehicle (saline) or exendin-4 (Ex4; I $\mu g / \mathrm{kg}$, i.p.) injection in intact sham-lesioned rats (PBNsham) and rats with ibotenic-acid lesions of the PBN (PBNx). Ex4 significantly reduced $0.3 \mathrm{M}$ sucrose solution intake in PBNsham rats but not PBNx rats. (b) The $0.3 \mathrm{M}$ sucrose meal size (+SEM) after vehicle or Ex4 injection in PBNsham and PBNx rats. Ex4 significantly reduced $0.3 \mathrm{M}$ sucrose solution intake PBNsham rats but not PBNx rats. $* P<0.05$. (c) The extent of intake suppression induced by Ex4 was positively and significantly correlated with the size of the lateral PBN (LPBN). Sham-lesioned rats (open circles); PBNx rats (filled circles). Rats with larger LPBN regions tended to show more sucrose intake reduction after Ex4 treatment (vehicle condition intake minus Ex4 condition intake $(\mathrm{ml})$ ).

individual lick cycles in a manner that reduced their ability to capture fluid from the spout. Despite this effect on lick efficiency, there was no increase in the proportion of ILIs in the 250-2000 ms range ( $p s>0.26$ ), suggesting that Ex4 did not produce a response comparable to the LiCl-induced taste aversion observed in the same rats (PBNsham: vehicle $=0.77$ $\pm 0.08 \%, \mathrm{Ex} 4=1.43 \pm 0.25 \%$; PBNx: vehicle $=0.92 \pm 0.11 \%$, Ex $4=1.30 \pm 0.31 \%$; compare with Table 1 ). 

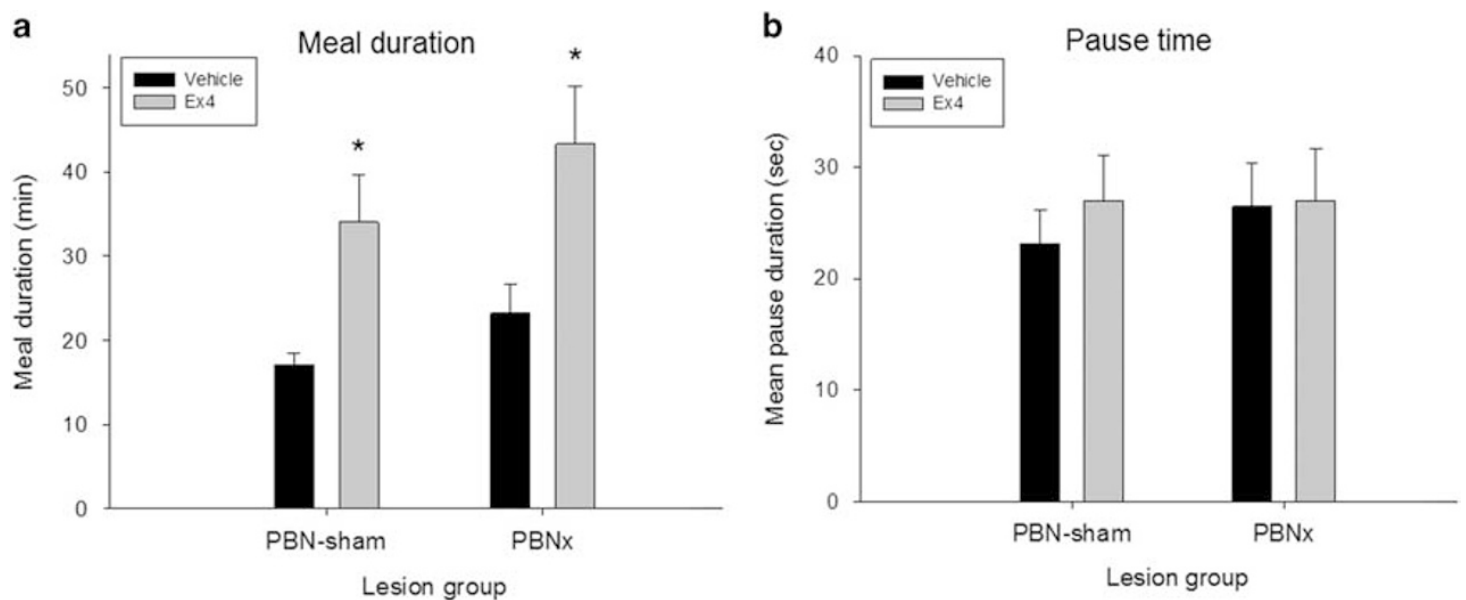

Figure 4 Exendin-4 (Ex4; I $\mu g / k g$, i.p.) significantly prolonged meal duration in both groups but did not prolong pauses between bursts of licking. (a) Mean meal duration (+SEM) after vehicle (saline) or exendin-4 (Ex4) injection in intact sham-lesioned rats (PBNsham) and rats with ibotenic-acid lesions of the PBN $(\mathrm{PBN} \times)$. Ex4 significantly prolonged the meal in both groups. (b) Mean pause duration (+SEM) after vehicle or Ex4 injection in PBNsham and PBNx rats. Ex4 did not affect the mean interval between bursts of licking in either lesion group. $* P<0.05$.

a



b

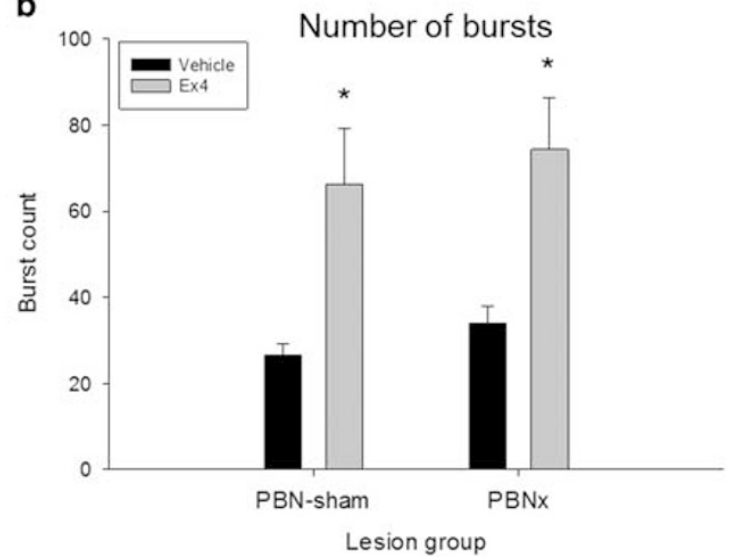

Figure 5 (a) Mean (+SEM) burst size per meal after vehicle (saline) or exendin-4 (Ex4; I $\mu$ g/ $/ \mathrm{kg}$, i.p.) injection in intact PBN sham-lesioned rats (PBNsham) and rats with ibotenic-acid lesions of the PBN (PBNx). Ex4 significantly reduced the average burst size in both groups. (b) Mean (+SEM) number of bursts per meal after vehicle or Ex4 injection in PBNsham and PBNx rats. Ex4 significantly increased the number of meal bursts in both groups. $* P<0.05$.

\section{DISCUSSION}

In this study we evaluated whether PBN function contributes to the well-documented hypophagic effects of the FDA-approved GLP-1 analog, Ex4. PBN lesions abolished hypophagic responses to Ex4 in rats consuming either regular chow of standard palatability, or a highly preferred palatable sucrose solution. These results show that the PBN is necessary for Ex4-induced intake reduction for the conditions tested in this study and they complement our prior work that indicated a physiological role for GLP-1Rs in the PBN in the control of food intake (Alhadeff et al, 2014). Together, the results suggest that the PBN likely contributes to hypophagic responses to long-acting systemic GLP-1R analogs.

The results of this study do not clarify whether the hypophagic effects of Ex4 were lost in PBNx rats because of the absence of direct Ex4 activation of GLP-1Rs in the PBN, or the loss of signals normally processed in the PBN that are relayed from Ex4/GLP-1R interactions processed elsewhere, or both. Because Ex4 crosses the blood-brain barrier (Kastin and Akerstrom, 2003), long-acting incretin mimetics such as Ex4 likely recruit pathways that would not normally be affected by endogenous plasma GLP-1 because of the rapid degradation of plasma GLP-1 by dipeptidyl peptidase-IV, in addition to the peripheral pathways that are normally stimulated by plasma GLP-1.

One pathway likely stimulated by systemic Ex4 delivery is that mediating visceral feedback. Systemic Ex4 activates GLP-1R receptors on the vagus nerve that in turn activate hindbrain NST relays; NST injections of Ex9 have been shown to impede satiation responses to gastric distension and hepatic portal glucose infusions (Hayes et al, 2009; Punjabi et al, 2014; Rüttimann et al, 2010). The PBN receives prominent and overlapping input from the rostral gustatory and caudal visceral sensory regions of the NST (Baird et al, 2001b; Fulwiler and Saper, 1984; Karimnamazi et al, 2002) 

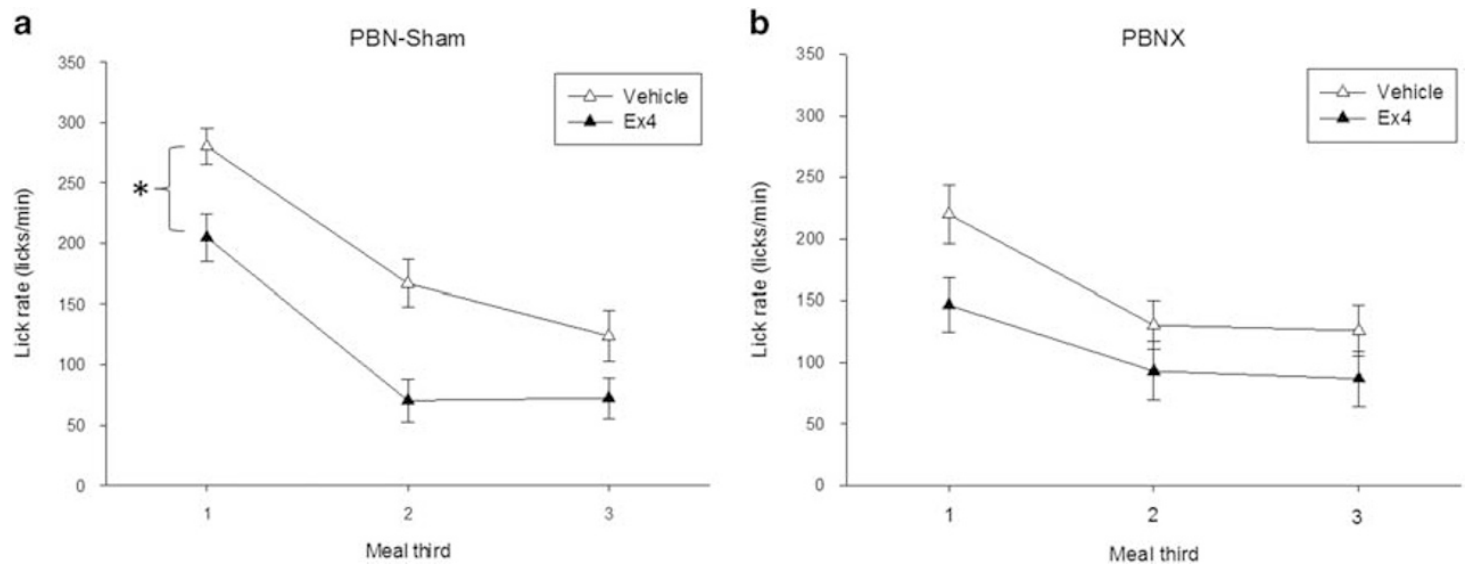

Figure 6 Mean ingestion rate plotted by meal thirds (means \pm SEM) after vehicle (saline) or exendin-4 (Ex4; I $\mu$ g/kg) injection in intact sham-lesioned rats (PBNsham) and rats with ibotenic-acid lesions of the PBN (PBNx). Meals were temporally divided into thirds and the average lick rate (licks/min) was determined for each meal third. (a) Mean lick rate by meal thirds after vehicle (open triangles) and Ex4 injection (filled triangles) in PBNsham rats. Ex4 significantly slowed the rate of ingestion in PBNsham rats relative to the vehicle condition for all three phases of the meal. (b) Mean lick rate by meal thirds after vehicle (open triangles) and Ex4 (filled triangles) injection in PBNx rats. PBNx rats showed a less robust reduction in ingestion rate after Ex4 injection, with no differences relative to vehicle in the last two thirds of the meal. $* P<0.05$.


Figure 7 Mean interlick interval (ILI) counts (5 ms bins) after vehicle (saline) or exendin-4 (Ex4; I $\mu \mathrm{g} / \mathrm{kg}$ ) injection in (a) intact sham-lesioned rats (PBNsham) and (b) rats with ibotenic-acid lesions of mostly the lateral PBN (PBNx). Ex4 significantly slowed the rate of licking within bursts in both lesion groups as indicated by a comparable right shift in the distribution of ILIs $<250 \mathrm{~ms}$. Note that PBNx rats exhibited more ILls (and therefore, licks) after Ex4 injection relative to the PBNsham group, reflecting the lack of intake reduction after Ex4 in PBNx rats.

and we have shown that gastric distension and gustatory stimuli modify electrophysiologically recorded neural impulse rates within the LPBN (Baird et al, 2001a,b), suggesting that PBN lesions would likely affect visceral and/or gustatoryrelated responses potentially affected by systemic Ex4. Therefore, to better identify gustatory and visceral-related responses to Ex4, we evaluated licking microstructure responses to a sucrose solution after Ex4 treatment in PBNsham and PBNx rats. To our knowledge, this is the first study to provide a detailed analysis of licking microstructure after systemic Ex4 treatment, and therefore initial discussion of Ex4 responses in PBNsham control rats is warranted.

\section{Ex4 Effects on Licking Microstructure in Intact Rats}

In PBNsham rats Ex4 reliably reduced intake for a normally preferred $(0.3 \mathrm{M})$ sucrose solution. However, the oromotor behaviors through which the intake reduction was expressed were quite different from microstructure responses observed for other typical pharmacological or natural satiationinducing treatments. Often, a treatment-induced reduction of food intake is achieved through an earlier termination of the meal (Berthoud et al, 2006; Davis et al, 1995; Davis and Smith, 1992; Schwartz et al, 1999; Scott and Moran, 2007; Williams et al, 2002), but we found that Ex4 markedly prolonged the meal. This suggests that rats must have ingested sucrose solution much more slowly after Ex4 treatment. As a meal progresses, the increasing size of the gastrointestinal load produces inhibitory feedback that leads to an increasingly rapid decline in ingestion rate (Davis, 1996; Davis and Smith, 1992). Increasing the caloric or volumetric properties of the ingesta by oral preload or direct caloric gastric or venous glucose preloads has been shown to reduce lick rate, burst count, and meal duration (but not mean burst size 
or lick rate within bursts), suggesting that the former measures reflect postingestive satiation (Baird et al, 2009; Davis et al, 2000; Davis and Smith, 1992; Dossat et al, 2013; Schwartz et al, 1999; Spector et al, 1998). Venous infusions of cholecystokinin and D-glucose have also been shown to reduce lick rate, burst number, and meal duration (Baird et al, 1999; Davis et al, 1995), further supporting a relationship between these measures and postingestive feedback signals. In PBNsham rats, Ex4 significantly reduced the rate of licking; however, this study departs from the studies above in that the rats continued to return to the spout to take numerous additional but smaller samples, resulting in more bursts and a longer meal, with no increase in the duration of pauses between bursts.

We conclude that systemic Ex4 enhanced visceral signals typically associated with postingestive feedback. However, Ex4 also increased the number of times the rats returned to the spout and reinitiated licking, as indicated by the increase in number of bursts and prolonged meal duration. These results suggest that competing behavioral responses were evoked that delayed a decision to terminate the meal. It is possible that the typical 'satiety sequence' (Antin et al, 1975; Young et al, 1974) is altered by Ex4, at least for the conditions tested here, a conclusion suggested previously after observing that central GLP-1R agonist infusions reduced intake but did not terminate sham feeding (Asarian et al, 1998). In line with this reasoning, some studies have reported relatively little change in the satiety ratio after Ex4 (Asarian et al, 1998; Scott and Moran, 2007), and a videographic analysis of behavior showed no increase in restful behavior after central GLP-1R agonist infusion (Asarian et al, 1998). In addition, studies analyzing meal patterns after Ex4 injection have reported a reduction in the average size of solid food (chow) meals, as we found (Asarian et al, 1998; Dossat et al, 2013; Scott and Moran, 2007; Williams et al, 2009), but reductions in meal duration and increases in the intermeal interval have been less consistently observed (Dossat et al, 2013; Scott and Moran, 2007). It is interesting to note that in rats with Roux-en-Y gastric bypass treatment, which is known to increase endogenous GLP-1 levels, meal size for a liquid diet was reduced but this was achieved by a significant reduction in lick volume (as observed here) with little to no effect on meal duration relative to sham-treated rats (Zheng et al, 2009). To our knowledge, our study is the first report of an increase in meal duration after Ex4 treatment and this difference may be a function of the type of food (sucrose versus chow) or the testing schedule ( $24 \mathrm{~h}$ access versus limited access), among other factors. Variations by food type would suggest that Ex4 responses vary as a function of tastant palatability and/or nutrient composition. For example, a few studies suggest that GLP-1R ligand effects may vary as a function of milk protein or fat consumption (Maersk et al, 2012; Olivos et al, 2014).

In several studies the average size of a burst of licking has been shown to positively correlate with taste evaluation such that rats exhibit larger bursts for more-preferred tastants (Baird et al, 2006; Davis, 1996; Davis and Smith, 1992; Spector et al, 1998). Satiating treatments generally reduce the mean size of a lick burst in later phases of the meal, and they have been shown to modify electrophysiological PBN and NST neuron responses to tastants (Baird et al, 1999, 2009, 2001b; Giza et al, 1992; Spector et al, 1998). We found that
Ex4 reduced of the mean burst size; however, there was no reduction in the initial rate of ingestion that is also regarded as an indicator of taste evaluation, as ingestion at the beginning of a meal is not influenced by inhibitory postingestive feedback related to meal consumption (Davis et al, 1995; Davis and Smith, 1992). Dossat et al, (2013) recently reported that nucleus accumbens injections of Ex9 increased lick burst size with little effect on the ILI or the inhibitory effects of a gastric preload, suggesting an effect more specific to taste evaluation. Mathes et al, (2012) also reported modest increases in the rate of licking for sucrose solutions in brief access tests across multiple sucrose solutions during $10 \mathrm{~s}$ trials after systemic Ex9 treatment (although Ex4 did not reduce lick rates in this study), and it is worth noting that taste receptor cells release GLP-1 into the vicinity of intragemmal taste fibers that express GLP-1 receptors (Shin et al, 2008). Therefore, it is possible that Ex4 interactions with a number of peripheral and central nervous system structures modify taste evaluation, and further scrutiny is needed.

In PBNsham rats Ex4 also potently affected measures of oromotor coordination. Ex4 significantly reduced the mean lick volume and it increased the mean duration of ILIs $<250 \mathrm{~ms}$, indicating that rats licked much more slowly within a burst and that the volume extracted from the spout per lick was smaller. These results highlight an aspect of GLP-1R treatment that has not received much attention. Studies have noted that Ex4 has little or modest depressive effect on gross measures of behavior such as bar pressing or locomotion (Alhadeff et al, 2014; Asarian et al, 1998), and the current study found that Ex4 rather increased the number of times rats approached the spout. Our findings, however, are consistent with a recent study that reported a very similar right shift in the principal ILI distribution after a comparable Ex4 dose (Mathes et al, 2012), and an earlier study evidenced a trend toward slower licking and smaller lick volumes as central GLP1-R agonist doses were increased (see Table 2 in Asarian et al, 1998; note also Zheng et al, 2009). ILIs $<250 \mathrm{~ms}$ are thought to reflect the output of a brainstem central pattern generator (CPG) and although slight variations can be induced by a variety of pharmacological, physiological, and environmental factors (HernandezMesa et al, 1985; Mamedov and Bures, 1984; Spector et al, 1996; Stanford et al, 2003; Weijnen, 1998), increases to the extent reported here have, to our knowledge, been rarely reported. The results strongly suggest that GLP-1Rexpressing neurons in oromotor hindbrain nuclei are involved in CPG rate-setting circuitry, consistent with studies showing GLP-1R mRNA expression in oromotor nuclei, particularly in areas of the reticular formation subjacent to the NST that provide premotor input to lingual motor neurons in the hypoglossal nucleus, including the lateral parvocellular reticular formation, intermediate zone of the reticular formation, and within mXII itself (Merchenthaler et al, 1999; Travers et al, 1997; Vrang and Larsen, 2010).

It is important to note that Ex4 treatment has been associated with malaise as shown by tests for pica and in two-bottle flavor aversion tests that can potentially complicate interpretations of Ex4 hypophagia (Kanoski et al, 2012; Kinzig et al, 2002). Although this study was not initially designed to explore this issue, licking measurement in the CTA tests afforded us the opportunity to compare licking responses after $\mathrm{LiCl}$ and after Ex4 treatment in the same rats. 
Table 2 Comparison of $\mathrm{LiCl}$ and Ex4 Effects on Licking Microstructure

\begin{tabular}{|c|c|c|c|c|}
\hline \multirow{2}{*}{$\begin{array}{l}\text { Lesion group } \\
\text { Treatment }\end{array}$} & \multicolumn{2}{|c|}{ PBNsham } & \multicolumn{2}{|c|}{ PBNx } \\
\hline & $\begin{array}{c}\text { LiCl } \\
\text { effect }\end{array}$ & $\begin{array}{c}\text { Ex4 } \\
\text { effect }\end{array}$ & $\begin{array}{c}\text { LiCl } \\
\text { effect }\end{array}$ & $\begin{array}{c}\text { Ex4 } \\
\text { effect }\end{array}$ \\
\hline Intake & $\downarrow$ & $\downarrow$ & - & - \\
\hline Meal duration & $\downarrow$ & $\uparrow$ & - & $\uparrow$ \\
\hline Burst size & $\downarrow$ & $\downarrow$ & - & $\downarrow$ \\
\hline First min lick rate & $\downarrow$ & - & - & - \\
\hline Number of bursts & $\uparrow$ & $\uparrow$ & - & $\uparrow$ \\
\hline Ingestion rate & $\downarrow$ & $\downarrow$ & - & - \\
\hline Pause duration & $\downarrow$ & - & - & - \\
\hline Pause time & $\uparrow$ & - & - & - \\
\hline Lick volume & $\downarrow$ & $\downarrow$ & $\downarrow$ & $\downarrow$ \\
\hline ILls $<250 \mathrm{~ms}$ & - & $\uparrow$ & - & $\uparrow$ \\
\hline \% ILIS 250-2000 ms & $\uparrow$ & - & - & - \\
\hline
\end{tabular}

Abbreviations: PBNsham, lesion control group; PBNx, parabrachial nucleus lesion. The same individual rats received $0.3 \mathrm{mEq}$ i.p. lithium chloride $(\mathrm{LiCl})$ injection or I $\mu g / \mathrm{kg}$ i.p. exendin-4 (Ex4) treatment in two separate experiments. Arrows indicate treatment effects on lick measures relative to control conditions. The responses to Ex4 and to $\mathrm{LiCl}$ are dissimilar within each group, whereas the responses to Ex4 are comparable in both groups, with the exception of intake and ingestion rate measures.

After CTA formation the PBNsham-treated rats showed a licking pattern that we have identified previously (Baird et al, 2005), but it was quite dissimilar from what we observed after Ex4 treatment in the same rats (see Table 2). Among other effects, PBNsham rats exhibited reduced meal duration, number of bursts, and initial lick rate after CTA training, whereas the same rats showed increases in meal duration and number of bursts, with no effect on initial lick rate after Ex4 treatment (Table 2). Moreover, ILIs that range from $250 \mathrm{~ms}$ to $2 \mathrm{~s}$ were markedly increased (fivefold) after CTA training but were not at all affected by Ex4, whereas ILIs $<250 \mathrm{~ms}$ were significantly lengthened by Ex 4 but not affected by CTA treatment (Table 2). Furthermore, it is worth noting that Ex4 continued to affect many measures of licking in PBNx rats that did not express a CTA (Table 1; discussed below). Overall, the effects of Ex4 on licking microstructure were distinct from those expressed after $\mathrm{LiCl}$ and this suggests that different underlying mechanisms accounted for the intake reductions.

\section{PBN Lesion Effects on Ex4 Hypophagia}

As anticipated, PBN lesions abolished CTA expression: $\mathrm{NaCl}$ intake was not significantly reduced after $\mathrm{LiCl}$ in PBNx rats. We further confirmed that the extent of the lesion, as measured by the depth of the LPBN, was significantly and inversely correlated to the extent of intake decline observed after LiCl. To our knowledge, this is the first study to evaluate licking microstructure responses after CTA training in rats with $\mathrm{PBN}$ lesions, and our results show that the pattern of CTA effects on licking was almost entirely reversed by the lesion. Of the 10 measures significantly altered by CTA training in PBNsham rats, only one measure, lick volume, remained modestly but significantly reduced after CTA training in PBNx rats (Table 2). Thus, PBN lesions produced a nearly complete impairment of CTA processing, supporting the generally accepted conclusion that PBN processing is necessary either for CTA formation or expression (see Reilly, 1999).

PBNx rats also failed to exhibit intake reductions either for sucrose or chow after Ex4 treatment, and this effect also correlated with measured lateral PBN depth. Given this common effect on intake measures across three different experiments, one might reasonably expect most of the microstructure measures affected by Ex4 in PBNsham rats to be largely unaffected in PBN-lesioned rats. However, PBNlesioned rats treated with Ex4 expressed, more or less, the same general pattern of changes in licking microstructure after Ex4 as did PBNsham rats (see Table 2). To some extent this would be expected given that systemic Ex4 crosses the blood-brain barrier and may therefore activate several brain structures that may (or may not) contribute to food intake processing, without contribution from the PBN. This is exemplified by our finding that the PBN lesion had no impact at all on the Ex4induced rightward shift in the ILI distribution in PBNsham rats, even though PBNsham rats expressed roughly half the number of ILIs (and therefore roughly half the licks) than did PBNx rats (Figure 7). Nevertheless, although it is clear that the $\mathrm{PBN}$ is not essential for the oromotor frequency effects of Ex4, some aspect of the PBN lesion was sufficient to impair the hypophagic response to Ex4.

Measures associated with gustatory evaluation were generally comparable across both lesion groups. The mean size of a lick burst was significantly reduced in both groups, whereas the initial rate of licking and the size of the first burst was not. Both groups also exhibited unexpectedly long meals that were produced primarily by increases in the number of bursts rather than by increases in pause duration, indicating that PBN lesions did not impair Ex4-induced motivation to approach the spout. We are tempted to conclude that Ex4 effects on taste evaluation (to the extent that they exist) do not require the participation of the PBN, but it is important to note that our lesions principally targeted the LPBN with less consistent damage to the caudal medial and ventral lateral PBN subnuclei, where more gustatory-responsive neurons are present ((Baird et al, 2001a, b; Fulwiler and Saper, 1984; Nishijo and Norgren, 1990; Sakai and Yamamoto, 1997; Tokita et al, 2012); see Figure 1b for example).

We determined, rather, that the PBN lesion abolished Ex4 hypophagia through a limitation on ingestion rate. Although Ex4 tended to reduce the rate of ingestion in both groups, the effect was attenuated in PBNx rats: PBNsham rats ingested much more slowly than PBNx rats after Ex4, particularly in the last two thirds of the meal. Rats with PBN lesions have been reported to have attenuated sensitivity to satiating treatments, and much of the vagal input from the viscerosensitive caudal NST is relayed to the LPBN (Baird et al, 2001a; Calingasan and Ritter, 1993; Flynn et al, 1991; Karimnamazi et al, 2002). Naturally satiating and viscerally aversive stimuli have been shown to activate neurons in the LPBN as measured through $c$-fos reactivity (Baird et al, 2001a; Paues et al, 2006; Sakai and Yamamoto, 1997), and we have also shown that LPBN neurons exhibit in vivo electrophysiological responses to gastric distension (Baird et al, 2001a). Together, the results suggest that PBNsham rats experienced 
more potent visceral feedback inhibition than $\mathrm{PBNx}$ rats after Ex4 treatment.

Our studies show that PBN neural function is necessary for the intake-suppressive effects of systemic Ex4 on chow and sucrose intake. Based on our analysis of licking microstructure, the PBN lesion abolished Ex4-induced hypophagia by attenuating the Ex4-enhanced gain of satiating postingestive feedback. This may be a result of (1) the loss of neuroanatomical connections of the PBN that processes first-order gustatory and visceral sensory signals from the NST as well as direct monosynaptic input from NST GLP-1-producing neurons (Alhadeff et al, 2014) and/or (2) the loss of GLP-1R processing within the PBN itself.

We also report here for the first time that systemic Ex4 in intact animals affects licking microstructure measures associated with a variety of feeding behaviors including ingestion rate, hedonic taste evaluation, appetitive behavior, and oromotor coordination. Our results highlight the value of using a detailed analysis of behavior as PBNx-induced blockade of intake reduction in two treatment paradigms (CTA and Ex4) was achieved in very different ways: $\mathrm{PBNx}$ abolished almost every licking microstructure measure underpinning CTA expression, but it only specifically blocked the suppression of ingestion rate induced by Ex4. Together with our prior work that shows that GLP-1R activation or blockade within the PBN is sufficient to modify food intake, the current results emphasize that the PBN GLP-1R contribution is a critical part of a distributed network of GLP-1R sites that contribute to Ex4 effects on feeding behavior.

\section{FUNDING AND DISCLOSURE}

The authors declare no conflict of interest.

\section{ACKNOWLEDGMENTS}

We thank Julian Scott, Mark Cort, Jeremy Levit, Shannon Townshend, Marcy Moore, Maureen Manning, and Daniel Berghoff for technical assistance. This work was funded by NIH-DC07389 (to J-PB), HHMI-52006280 (to J-PB and HR), and Amherst College. HJG has received funding from Novo Nordisk where he is also on the Advisory Board; however, the support from this company has no relevance to this study.

\section{REFERENCES}

Alhadeff AL, Baird J-P, Swick JC, Hayes MR, Grill HJ (2014). Glucagon-like peptide-1 receptor signaling in the lateral parabrachial nucleus contributes to the control of food intake and motivation to feed. Neuropsychopharmacology 39: 2233-2243.

Alhadeff AL, Grill HJ (2014). Hindbrain nucleus tractus solitarius glucagon-like peptide-1 receptor signaling reduces appetitive and motivational aspects of feeding. Am J Physiol Regul Integr Comp Physiol 307: R465-R470.

Antin J, Gibbs J, Holt J, Young RC, Smith GP (1975). Cholecystokinin elicits the complete behavioral sequence of satiety in rats. J Comp Physiol Psychol 89: 784-790.

Asarian L, Corp ES, Hrupka B, Geary N (1998). Intracerebroventricular glucagon-like peptide-1 (7-36) amide inhibits sham feeding in rats without eliciting satiety. Physiol Behav 64: $367-372$.
Baird J-P, Choe A, Loveland JL, Beck J, Mahoney CE, Lord JS et al (2009). Orexin-A hyperphagia: hindbrain participation in consummatory feeding responses. Endocrinology 150: 1202-1216.

Baird J-P, Gray NE, Fischer SG (2006). Effects of neuropeptide Y on feeding microstructure: dissociation of appetitive and consummatory actions. Behav Neurosci 120: 937-951.

Baird J-P, St John SJ, Nguyen EA-N (2005). Temporal and qualitative dynamics of conditioned taste aversion processing: combined generalization testing and licking microstructure analysis. Behav Neurosci 119: 983-1003.

Baird JP, Grill HJ, Kaplan JM (1999). Effect of hepatic glucose infusion on glucose intake and licking microstructure in deprived and nondeprived rats. Am J Physiol 277: R1136-R1143.

Baird JP, Travers JB, Travers SP (2001a). Parametric analysis of gastric distension responses in the parabrachial nucleus. Am J Physiol Regul Integr Comp Physiol 281: R1568-R1580.

Baird JP, Travers SP, Travers JB (2001b). Integration of gastric distension and gustatory responses in the parabrachial nucleus. Am J Physiol Regul Integr Comp Physiol 281: R1581-R1593.

Baraboi E-D, St-Pierre DH, Shooner J, Timofeeva E, Richard D (2011). Brain activation following peripheral administration of the GLP-1 receptor agonist exendin-4. Am J Physiol Regul Integr Comp Physiol 301: R1011-R1024.

Barrera JG, Jones KR, Herman JP, D'Alessio DA, Woods SC, Seeley RJ (2011). Hyperphagia and increased fat accumulation in two models of chronic CNS glucagon-like peptide-1 loss of function. J Neurosci 31: 3904-3913.

Becskei C, Grabler V, Edwards GL, Riediger T, Lutz TA (2007). Lesion of the lateral parabrachial nucleus attenuates the anorectic effect of peripheral amylin and CCK. Brain Res 1162: 76-84.

Berthoud H-R, Sutton GM, Townsend RL, Patterson LM, Zheng H (2006). Brainstem mechanisms integrating gut-derived satiety signals and descending forebrain information in the control of meal size. Physiol Behav 89: 517-524.

Blevins T (2011). Control of postprandial glucose levels with insulin in type 2 diabetes. Postgrad Med 123: 135-147.

Bond A (2006). Exenatide (Byetta) as a novel treatment option for type 2 diabetes mellitus. Proc (Bayl Univ Med Cent) 19: 281-284.

Bullock BP, Heller RS, Habener JF (1996). Tissue distribution of messenger ribonucleic acid encoding the rat glucagon-like peptide-1 receptor. Endocrinology 137: 2968-2978.

Buse JB, Bergenstal RM, Glass LC, Heilmann CR, Lewis MS, Kwan AYM et al (2011). Use of twice-daily exenatide in Basal insulin-treated patients with type 2 diabetes: a randomized, controlled trial. Ann Intern Med 154: 103-112.

Calingasan NY, Ritter S (1993). Lateral parabrachial subnucleus lesions abolish feeding induced by mercaptoacetate but not by 2-deoxy-D-glucose. Am J Physiol 265: R1168-R1178.

Davis JD (1996). Deterministic and probabilistic control of the behavior of rats ingesting liquid diets. Am J Physiol 270: R793-R800.

Davis JD, Smith GP (1992). Analysis of the microstructure of the rhythmic tongue movements of rats ingesting maltose and sucrose solutions. Behav Neurosci 106: 217-228.

Davis JD, Smith GP, Kung TM (1995). Cholecystokinin changes the duration but not the rate of licking in vagotomized rats. Behav Neurosci 109: 991-996.

Davis JD, Smith GP, Singh B, McCann DP (2000). The impact of milk-derived unconditioned and conditioned negative feedback on the microstructure of ingestive behavior. Physiol Behav 70: 279-285.

Dossat AM, Diaz R, Gallo L, Panagos A, Kay K, Williams DL (2013). Nucleus accumbens GLP-1 receptors influence meal size and palatability. Am J Physiol Endocrinol Metab 304: E1314-E1320.

Dossat AM, Lilly N, Kay K, Williams DL (2011). Glucagon-like peptide 1 receptors in nucleus accumbens affect food intake. J Neurosci 31: 14453-14457. 
Edwards CM, Stanley SA, Davis R, Brynes AE, Frost GS, Seal LJ et al (2001). Exendin-4 reduces fasting and postprandial glucose and decreases energy intake in healthy volunteers. Am J Physiol Endocrinol Metab 281: E155-E161.

Flynn FW, Grill HJ, Schulkin J, Norgren R (1991). Central gustatory lesions: II. Effects on sodium appetite, taste aversion learning, and feeding behaviors. Behav Neurosci 105: 944-954.

Fulwiler CE, Saper CB (1984). Subnuclear organization of the efferent connections of the parabrachial nucleus in the rat. Brain Res 319: 229-259.

Giza BK, Scott TR, Vanderweele DA (1992). Administration of satiety factors and gustatory responsiveness in the nucleus tractus solitarius of the rat. Brain Res Bull 28: 637-639.

Göke R, Fehmann HC, Linn T, Schmidt H, Krause M, Eng J et al (1993). Exendin-4 is a high potency agonist and truncated exendin-(9-39)-amide an antagonist at the glucagon-like peptide 1-(7-36)-amide receptor of insulin-secreting beta-cells. J Biol Chem 268: 19650-19655.

Grill HJ (2010). Leptin and the systems neuroscience of meal size control. Front Neuroendocrinol 31: 61-78.

Hayes MR, Bradley L, Grill HJ (2009). Endogenous hindbrain glucagon-like peptide-1 receptor activation contributes to the control of food intake by mediating gastric satiation signaling. Endocrinology 150: 2654-2659.

Hayes MR, Skibicka KP, Grill HJ (2008). Caudal brainstem processing is sufficient for behavioral, sympathetic, and parasympathetic responses driven by peripheral and hindbrain glucagon-like-peptide-1 receptor stimulation. Endocrinology 149: 4059-4068.

Hernandez-Mesa N, Mamedov Z, Bures J (1985). Operant control of the pattern of licking in rats. Exp Brain Res 58: 117-124.

Jessen L, Aulinger BA, Hassel JL, Roy KJ, Smith EP, Greer TM et al (2012). Suppression of food intake by glucagon-like peptide-1 receptor agonists: relative potencies and role of dipeptidyl peptidase-4. Endocrinology 153: 5735-5745.

Kanoski SE, Fortin SM, Arnold M, Grill HJ, Hayes MR (2011). Peripheral and central GLP-1 receptor populations mediate the anorectic effects of peripherally administered GLP-1 receptor agonists, liraglutide and exendin-4. Endocrinology 152: 3103-3112.

Kanoski SE, Rupprecht LE, Fortin SM, De Jonghe BC, Hayes MR (2012). The role of nausea in food intake and body weight suppression by peripheral GLP-1 receptor agonists, exendin-4 and liraglutide. Neuropharmacology 62: 1916-1927.

Karimnamazi H, Travers JB (1998). Differential projections from gustatory responsive regions of the parabrachial nucleus to the medulla and forebrain. Brain Res 813: 283-302.

Karimnamazi H, Travers SP, Travers JB (2002). Oral and gastric input to the parabrachial nucleus of the rat. Brain Res 957: 193-206.

Kastin AJ, Akerstrom V (2003). Entry of exendin-4 into brain is rapid but may be limited at high doses. Int J Obes Relat Metab Disord 27: 313-318.

Kinzig KP, D'Alessio DA, Seeley RJ (2002). The diverse roles of specific GLP-1 receptors in the control of food intake and the response to visceral illness. J Neurosci 22: 10470-10476.

Lundy RF, Norgren R (2004). Activity in the hypothalamus, amygdala, and cortex generates bilateral and convergent modulation of pontine gustatory neurons. J Neurophysiol 91: 1143-1157.

Maersk M, Belza A, Holst JJ, Fenger-Grøn M, Pedersen SB, Astrup A et al (2012). Satiety scores and satiety hormone response after sucrose-sweetened soft drink compared with isocaloric semi-skimmed milk and with non-caloric soft drink: a controlled trial. Eur J Clin Nutr 66: 523-529.

Mamedov Z, Bures J (1984). Sensory feedback modulates the central pacemaker of licking in rats. Neurosci Lett 45: 1-6.

Mathes CM, Bueter M, Smith KR, Lutz TA, Roux CW, le, Spector AC (2012). Roux-en-Y gastric bypass in rats increases sucrose taste-related motivated behavior independent of pharmacological GLP-1-receptor modulation. Am J Physiol Regul Integr Comp Physiol 302: R751-R767.

McMahon LR, Wellman PJ (1998). PVN infusion of GLP-1-(7-36) amide suppresses feeding but does not induce aversion or alter locomotion in rats. Am J Physiol 274: R23-R29.

Merchenthaler I, Lane M, Shughrue P (1999). Distribution of prepro-glucagon and glucagon-like peptide-1 receptor messenger RNAs in the rat central nervous system. J Comp Neurol 403: 261-280.

Nakagawa A, Satake H, Nakabayashi H, Nishizawa M, Furuya K, Nakano S et al (2004). Receptor gene expression of glucagon-like peptide-1, but not glucose-dependent insulinotropic polypeptide, in rat nodose ganglion cells. Auton Neurosci 110: 36-43.

Nishijo H, Norgren R (1990). Responses from parabrachial gustatory neurons in behaving rats. J Neurophysiol 63: 707-724.

Norgren R, Hajnal A, Mungarndee SS (2006). Gustatory reward and the nucleus accumbens. Physiol Behav 89: 531-535.

Olivos DR, McGrath LE, Turner CA, Montaubin O, Mietlicki-Baase EG, Hayes MR (2014). Intraduodenal milk protein concentrate augments the glycemic and food intake suppressive effects of DPP-IV inhibition. Am J Physiol Regul Integr Comp Physiol 306: R157-R163.

Paues J, Mackerlova L, Blomqvist A (2006). Expression of melanocortin-4 receptor by rat parabrachial neurons responsive to immune and aversive stimuli. Neuroscience 141: 287-297.

Pelchat ML, Grill HJ, Rozin P, Jacobs J (1983). Quality of acquired responses to tastes by Rattus norvegicus depends on type of associated discomfort. J Comp Psychol 97: 140-153.

Punjabi M, Arnold M, Rüttimann E, Graber M, Geary N, Pacheco-López G et al (2014). Circulating glucagon-like peptide-1 (GLP-1) inhibits eating in male rats by acting in the hindbrain and without inducing avoidance. Endocrinology 155: $1690-1699$.

Reilly S (1999). The parabrachial nucleus and conditioned taste aversion. Brain Res Bull 48: 239-254.

Renner E, Puskás N, Dobolyi A, Palkovits M (2012). Glucagon-like peptide-1 of brainstem origin activates dorsomedial hypothalamic neurons in satiated rats. Peptides 35: 14-22.

Rinaman L (2010). Ascending projections from the caudal visceral nucleus of the solitary tract to brain regions involved in food intake and energy expenditure. Brain Res 1350: 18-34.

Rüttimann EB, Arnold M, Geary N, Langhans W (2010). GLP-1 antagonism with exendin (9-39) fails to increase spontaneous meal size in rats. Physiol Behav 100: 291-296.

Sakai N, Yamamoto T (1997). Conditioned taste aversion and c-fos expression in the rat brainstem after administration of various USs. Neuroreport 8: 2215-2220.

Schwartz GJ, Salorio CF, Skoglund C, Moran TH (1999). Gut vagal afferent lesions increase meal size but do not block gastric preloadinduced feeding suppression. Am J Physiol 276: R1623-R1629.

Scott KA, Moran TH (2007). The GLP-1 agonist exendin-4 reduces food intake in nonhuman primates through changes in meal size. Am J Physiol Regul Integr Comp Physiol 293: R983-R987.

Shin Y-K, Martin B, Golden E, Dotson CD, Maudsley S, Kim W et al (2008). Modulation of taste sensitivity by GLP-1 signaling. J Neurochem 106: 455-463.

Spector AC, Klumpp PA, Kaplan JM (1998). Analytical issues in the evaluation of food deprivation and sucrose concentration effects on the microstructure of licking behavior in the rat. Behav Neurosci 112: 678-694.

Spector AC, Redman R, Garcea M (1996). The consequences of gustatory nerve transection on taste-guided licking of sucrose and maltose in the rat. Behav Neurosci 110: 1096-1109.

Stanford JA, Vorontsova E, Surgener SP, Gerhardt GA, Fowler SC (2003). Aged Fischer 344 rats exhibit altered orolingual motor function: relationships with nigrostriatal neurochemical measures. Neurobiol Aging 24: 259-266. 
Szayna M, Doyle ME, Betkey JA, Holloway HW, Spencer RG, Greig NH et al (2000). Exendin-4 decelerates food intake, weight gain, and fat deposition in Zucker rats. Endocrinology 141: 1936-1941.

Tokita K, Yamamoto T, Boughter JD (2012). Gustatory neural responses to umami stimuli in the parabrachial nucleus of C57BL/ 6J mice. J Neurophysiol 107: 1545-1555.

Travers JB, Dinardo LA, Karimnamazi H (1997). Motor and premotor mechanisms of licking. Neurosci Biobehav Rev 21: 631-647.

Trifunovic R, Reilly S (2001). Medial versus lateral parabrachial nucleus lesions in the rat: effects on cholecystokinin- and D-fenfluramine-induced anorexia. Brain Res 894: 288-296.

Vahl TP, Tauchi M, Durler TS, Elfers EE, Fernandes TM, Bitner RD et al (2007). Glucagon-like peptide-1 (GLP-1) receptors expressed on nerve terminals in the portal vein mediate the effects of endogenous GLP-1 on glucose tolerance in rats. Endocrinology 148: 4965-4973.

Vrang N, Larsen PJ (2010). Preproglucagon derived peptides GLP-1, GLP-2 and oxyntomodulin in the CNS: role of peripherally secreted and centrally produced peptides. Prog Neurobiol 92 442-462.

Weijnen JA (1998). Licking behavior in the rat: measurement and situational control of licking frequency. Neurosci Biobehav Rev 22: 751-760.

Williams DL, Baskin DG, Schwartz MW (2009). Evidence that intestinal glucagon-like peptide-1 plays a physiological role in satiety. Endocrinology 150: 1680-1687.

Williams DL, Grill HJ, Weiss SM, Baird J-P, Kaplan JM (2002). Behavioral processes underlying the intake suppressive effects of melanocortin 3/4 receptor activation in the rat. Psychopharmacology (Berl) 161: 47-53.

Young RC, Gibbs J, Antin J, Holt J, Smith GP (1974). Absence of satiety during sham feeding in the rat. J Comp Physiol Psychol 87: 795-800.

Zheng H, Shin AC, Lenard NR, Townsend RL, Patterson LM, Sigalet DL et al (2009). Meal patterns, satiety, and food choice in a rat model of Roux-en-Y gastric bypass surgery. Am J Physiol Regul Integr Comp Physiol 297: R1273-R1282. 